\title{
India's Climate Policy: Squaring the Circle
}

\author{
D. Raghunandan
}

\begin{abstract}
The Durban Platform process towards a new global climate agreement has thrown open for debate all issues, including those earlier settled in the Kyoto Protocol. Any new compact must ensure sharply reduced global emissions as required by science, while adhering to principles of equity between nations regarding utilisation of the atmospheric commons. India faces serious difficulties in reconciling international expectations and domestic developmental priorities. India's recent economic growth, increased emissions and great power ambitions suggest greater need and capacity for mitigation whereas its continuing burden of income and energy poverty severely inhibits additional commitments. This article examines the factors driving India's negotiating position. It argues that an equitable development perspective within India, a clearer appreciation of climate science and its likely impacts, and a more balanced view of its diplomatic interests especially in the global South, would yield a more coherent position than a US or first worlddriven agenda and inevitable defensive reactions.
\end{abstract}

The 17th Conference of Parties (COP17) at Durban represents a watershed, for good or ill depending on your point of view, in the international negotiations towards a global climate agreement. COP17 did not agree on a second commitment period of the Kyoto Protocol for 2012 onwards, nor did it finalise terms of an alternative agreement. Yet it did set in motion a definitive process - the Durban Platform for Enhanced Action - and delineated some guidelines for a new agreement to be drawn up by 2015 and take effect in 2020 . While there are of course many interpretations of the Durban outcome, there is broad concurrence that the Durban Platform is neither completely openended nor fully predefined (Dubash 2012b; Bidwai 2011; Levi 2011; Raghunandan 2011; Rajamani 2011). The extremely brief Durban Platform text calls for a new 'protocol, another legal instrument or an agreed outcome with legal force', the last phrase being inserted at India's insistence and breaking the deadlock (UNFCCG 2011). The new arrangement would be based on 'options for a range of actions', clearly quite different from commitments as under Kyoto, and would be 'applicable to all parties' rather than follow the Kyoto principle of common but differentiated responsibilities for developed and developing countries. The additional phrase that this arrangement would be 'under the [UN Framework] Convention' is open to widely varying interpretations and adds little clarity. The Durban Platform therefore throws open to debate virtually all issues under negotiation, including many settled earlier under the Kyoto Protocol, but appears to tilt the balance in favour of developed countries by not insisting on stiff emission reduction targets and also as we shall see by circumscribing the negotiating positions of developing nations. Within these limitations, however, there may still remain some scope for shaping the architecture of a new and meaningful global system for regulating greenhouse gas $(\mathrm{GHG})$ emissions into the atmosphere.

Proceedings at Durban, read along with those at the preceding Cancun and Copenhagen summits, point to developed country positions playing a dominant role in shaping the final outcome. However, despite large developing nations such as China and India historically not having advanced decisive formulations, the positions of these nations, both with high emissions with high growth rates, will likely be of considerable significance and could have a major 
impact on outcomes. The iconic image from the last day at the Durban conference, of India's Environment Minister Jayanthi Natarajan surrounded by envoys of the USA, EU and key developing country players all trying to persuade her to sign off on an agreed formulation, is indicative of the key role these large developing countries could play. It also dramatically portrayed India's isolation at Durban.

Set against this background, this article seeks to examine what role India can or should play in the Durban Platform process in the months ahead, and what factors would drive India's positions. Much as one may like to, space limitations do not permit a discursive examination of India's positions through the tortuous course of international climate negotiations over almost two decades. ${ }^{2}$ Their main elements are, however, summarised very briefly even at the risk of oversimplification, mainly to enable readers unfamiliar with the subject to follow the ensuing discussions.

\section{Main elements of India's position}

From the outset, India had pioneered steps towards formulation of, and firmly anchored its position in, the principle embodied in the UN Framework Convention on Climate Change (UNFCGG) that underpins the Kyoto Protocol and all climate negotiations. This principle maintains that developed countries, being primarily responsible for the accumulated atmospheric GHGs and for the continued high per capita emissions which together cause the climate problem, bear the main responsibility for the requisite clean-up through reduction of GHG emissions and for the transfer of funds and technology to enable developing countries to cope with climate impacts and to adopt such mitigation measures as they can (UNFCGG 1992). India had long been a staunch advocate and defender of the Kyoto Protocol principle of 'common but differentiated responsibility' or CBDR derived from the Convention, and the firewall erected in it between the legally binding obligations of developed countries and the voluntary actions developing countries may take according to their 'respective capabilities' or $\mathrm{RC},{ }^{3}$ subject to transfer of funds and technologies from developed countries. India stoutly and for a long time resisted efforts by the USA and other developed nations to pressure India and other large developing countries to dismantle this firewall and accept a single framework for mitigation obligations.

However, in the run up to Copenhagen, in the face of mounting pressure from developed nations and keeping in mind announcements of mitigation commitments by other large developing countries such as China, Mexico, South Africa and Indonesia, India announced unilateral measures to reduce its emissions intensity by $20-25$ per cent by 2020 compared to current levels. This was formally placed on record in the informal Copenhagen Accord and its pledge-and-review system applicable to all countries that was subsequently formalised at Cancun. The factors behind and implications of this position for India's stance is the subject of much debate within India and will of course be discussed here.

Meanwhile, the USA refused to join the Kyoto Protocol but participated in all COP deliberations as a signatory to the Convention and kept pushing its interests, which other nations pandered to in the vain hope of getting the USA on board. Many other developed countries followed the US lead while the EU, which earlier favoured deep emission cuts, began watering down its commitments and veered toward the US position of seeking a single framework for both developed and developing countries, as in the Copenhagen pledge-and-review system, which major developing nations agreed to. How India, or for that matter other developing countries, factor these developed country positions into their their own stance is not very clear and is another issue addressed in this article.

In the midst of all these varying and often divergent positions, it was India that found itself isolated at Durban from both developed and developing countries, notably the Least Developed Countries (LDCs) and the Small Island Development States (SIDS), when it refused to sign on to the idea of a new legally binding treaty before its terms became clear. While finally agreeing to a consensus declaration including a term that India perceived to be a less definitive formulation of the nature of any future agreement, India insisted that the original idea of equity between nations should remain the guiding principle in any future agreement. India now needs to work out, with careful attention to detail and nuance, the position it would take in the forthcoming negotiations under the Durban 
Platform, the broad goal it sets for the new global climate agreement, and the approach it should adopt in order to achieve this goal or as much of it as possible.

\section{Science and the global goals}

I shall begin with the global emission control goals for mitigating climate change because, so often while discussing the negotiations and the realpolitik that comes into play, the overall goal and what is sought to be achieved are forgotten, much to the detriment of the debate.

The Durban outcome has clearly left the world no better off than before. Far from agreeing on terms for the second commitment period of the Kyoto Protocol - a goal originally set for Copenhagen two years before that at Bali - the Durban summit in the main postponed this to 2020. This despite the broad scientific consensus represented in the IPCG Fourth Assessment Report (IPCG/AR4) that atmospheric GHG concentrations are close to a 'tipping point' beyond which lies possible irreversible climate change, and that urgent mitigation actions are required including a reduction of global emissions of 50 per cent by 2050 and a reduction of emissions by developed countries of up to 40 per cent compared to 1990 levels by 2020 and 90-95 per cent by 2050 (IPCC 2007a: 36-37ff). Many authoritative agencies and groups estimate that the voluntary pledges made at Cancun by 85 nations, following the pattern set in the Copenhagen Accords and which are presumed to prevail till the new dispensation comes into play, will see global average temperatures rise by 3-3.5 $\mathrm{C}$ (Kartha and Erickson 2011; UNEP 2011). This is far above the oft-repeated goal, reiterated in Durban, of limiting global average temperature rise to $2^{\circ} \mathrm{C}$. It is worth recalling that this egregious fiction was first enunciated at G8 Summits and regrettably joined in by leading developing countries including India, China, Brazil and South Africa in the so-called 'Major Economies Forum' which later morphed into the G20. ${ }^{4}$ The problem of course is that all the parties know full well that, with the pledges currently on the table, this goal cannot be achieved. Indeed, the goal should never have been set in terms of temperature in the first place, since this is an outcome that cannot be directly controlled; it should have been set in terms of emissions or atmospheric GHG concentrations that can be measured and regulated.
The low ambition for emission reduction targets has serious consequences, especially for India and South Asia in general, which are projected to be among the regions worst affected by climate change (IPCG 2007b). Regrettably, while being noted pro forma in official policy statements by India, the need to reduce impacts by raising global mitigation targets has not been factored in as a national security imperative to be achieved through global agreements under the UNFCGC. This may appear to be an unkind and inapt remark when considered against the callousness of the USA and its allies in the global North who, despite being responsible for over three-quarters of the accumulated stock of carbon in the atmosphere, have consciously and consistently evaded their primary responsibility to clean up the pollution they have caused. The point here, however, is that India's stance and the role it plays in international negotiations would have, and should have, been quite different had India taken greater cognisance of this imperative.

It is indeed ironic that, while India is very similar to most LDGs and SIDS in terms of energy poverty, low per capita emissions, potential impact of and vulnerability to climate change, it has found itself or rather has chosen to locate itself in the negotiations not along with these countries which played a key role in pushing the Durban summit towards an agreement, but among the economically advanced nations of the global North. India's isolation at Durban was not so much a diplomatic failure as one stemming from India's negotiating position being weakly grounded both in global climate goals and India's vulnerabilities.

\section{Climate policy and foreign policy}

To be fair, India finds itself in a cleft stick, especially so in recent years due to its growing economy. This newly acquired stature, and India's enthusiasm in reorienting its foreign policy towards realising its great power aspirations, have created expectations and obligations on the international stage. At the same time, despite India's supposedly booming economy, more than half its population continues to be mired in poverty with many development indicators on a par with the poorest nations. India has not yet reconciled these contradictory trends in its development story in respect of India's climate negotiating stance. 
As I have discussed elsewhere at length (Raghunandan 2012), India had allowed itself to be herded into a common position with the USA and other Northern nations, starting with the 'G8+5' summits and so-called MEF Statements referring to the global goal of $2^{\circ} \mathrm{C}$, mitigation efforts by 'all countries' and so on. It is important to note that India shifted from its traditional Kyoto Protocol developing country stance to one of taking on mitigation obligations without obtaining the requisite deep emission cuts or other commitments from developed nations, chiefly due to a pronounced pro-US foreign policy slant. This genie was not easily to go back into the bottle, and has come to haunt India from Copenhagen through Durban with ominous portents for the future.

At Copenhagen, the USA forged a common position with the G5 'emerging economies' including India and China who, like the USA, were reluctant to accept binding emission cuts, and pushed through the pledge-and-review model of the Copenhagen Accord, leaving the EU out in the cold. At Durban, the EU turned the tables by building a powerful coalition on the Conference floor with the Africa Group and the Island States, the 'conscience of the climate summits', and secured acceptance of its proposal for a new legally binding regulatory instrument. The pressure of numbers, the clamour for a positive decision by the COP, and the powerful sentiment favouring concrete steps to tackle the climate crisis viewed as an existential threat by the Island States and most LDCs, together pressured the USA, China and some others into shelving their reservations, leaving India famously and petulantly alone.

India needs to seriously ponder its complete misreading of the mood of the COP delegates representing most nations of the world, especially India's natural allies among the developing countries. India needlessly exposed itself to the poignant even if incorrect perception ${ }^{5}$ voiced by Grenada's lead delegate and spokesperson for the Island States, that India wanting more leeway for development without committing to emissions controls implied that 'while they develop, we die' (Black 2011). India's opposition at Durban to the EU proposal for a new legally binding instrument, even though no commitments had been spelt out, also baffled legal experts (Rajamani 2011). It is also regrettable that India has not sought alliances with EU nations with whom, historically as well as by current governance structures and practices, India shares a common preference for regulation.

The global climate negotiations have of course always been about political economy and therefore bring geopolitics into play. Climate policy, though, requires a longer-term and truly strategic view that cannot be traded-off against or made subservient to foreign policy goals. Since India's position in climate negotiations has been so heavily shaped by its perspective on international relations, India should perhaps look to overhaul the diplomacy linked to its climate policy.

\section{Capability and mitigation action}

With a revaluation of the science, India also needs to rethink its understanding of what it, along with other countries, needs to do to combat the climate crisis. Lack of understanding of the need for serious mitigation action by India, and failure to integrate this into its negotiating position, has detracted from the Indian role in climate negotiations and contributed to the disconnect noted between India and other developing countries. Notwithstanding similarities in human development indicators between India and the LDCs, the Africa Group and the Island States, it is evident that, along with deep cuts by developed countries, the emissions growth trajectory of India and other large developing countries, especially China, needs trimming, ${ }^{6}$ and these countries have the capability to do this. This elephant has been in the room since release of the IPCC Fourth Assessment Report (IPCC/AR4) in 2007 which also called upon developing countries to 'deviate below their projected baseline emissions' (IPCG 2007a: 89-90).

Again as discussed in greater detail elsewhere (Raghunandan 2012; Raghunandan et al. 2007), even simple back-of-envelope calculations would clarify the issue. Out of total global emissions of around 49 Giga tonnes (Gt) [1 Giga tonne = 1 billion tonnes] of carbon dioxide equivalent in 2005, developing country emissions were already at around $26.5 \mathrm{Gt}$ and were growing as a proportion of emissions by all countries since emission flows by most developed nations were levelling off. If global emissions are to come down by 50 per cent or about $24.5 \mathrm{Gt}$ as called for by IPCC/AR4 by 2050, this obviously means that emissions by developing countries must come 
down even if developed country emissions are reduced to nil. ${ }^{7}$ Detailed modelling exercises by scholars in India (Kanitkar et al. 2010) taking historical emissions into account have brought out the kinds of moderated emissions trajectories that India may have to follow at current economic growth rates in order to meet the global $2^{\circ} \mathrm{C}$ limit. There should be similar trajectories for other developing countries of slower emissions growth gradually peaking and then declining sometime in the medium term, as well as immediate and deep emission cuts by developed countries.

The Indian government belatedly and after considerable prodding took cognisance of this in the lead-up to Copenhagen, but badly mishandled incorporating it into its basic negotiating position. The decision to reduce emissions intensity by 20-25 per cent below current levels by 2020 was announced by India long after China had declared a 40 per cent reduction in emissions intensity and also after absolute cuts were announced by South Africa, Mexico and Indonesia. Contrary to recommendations by many experts, scholars and civil society organisations (Campaign for Progressive Climate Action and Policy 2009; Raghunandan et al. 2007), India made its announcement as a unilateral measure rather than as conditional upon deep emissions cuts and transfer of finance and technology by developed nations.

Consequently, these significant mitigation pledges announced by India, China and other developing countries could not be used as leverage to extract deeper emissions cut commitments by developed countries, and did not stand out in the public eye at Copenhagen. In fact, they were brushed aside as old hat during negotiations by the USA and other developed nations who demanded further developing country concessions at the summit! This despite a confidential UN assessment that the voluntary commitments by developing countries totalled about 5.2 billion tonnes, far exceeding those by industrialised nations amounting to only 2.1-3.4 billion tonnes. ${ }^{8}$

Despite these shortcomings, the decision by India to slow down emission growth rates marked a significant shift in India's climate policy which had hitherto been glued to a do-nothing position. The earlier position that India was not required to do anything since it had not caused the problem, had substantial justification especially as it was in conformity with the Kyoto Protocol, even if it outlived its usefulness. But in the changed situation of high economic growth and related increase of emissions in India, combined with the compelling prognosis of IPCC/AR4, there is a strong rationale for a position that India, now with undoubtedly greater capability than before, is willing to be part of the solution despite not having been part of the problem. The conditionality suggested above could be reintroduced under the Durban Platform process along with, as a bargaining chip, consideration of the legally binding option which India has little reason to fear (Desai 2011).

Based on the science and on the ethical principle of 'common but differentiated responsibility and respective capability', adopting such a position as a well-reasoned choice, rather than merely taking a step or two in response to external pressure, has several features to commend it. It enables India to intervene in the international debate more positively and would demonstrate India's seriousness about and responsiveness to the climate crisis and its grave consequences for India and other developing countries. Together with more proactive diplomacy, it could be better leveraged to pressure developed countries on issues of concern to developing nations such as more ambitious mitigation targets and transfers of finance and technology. It would also bring India more in line with the LDCs, Island States and other developing nations.

\section{Towards a new agreement}

Going forward, it also behoves India to move beyond its traditional defensive posture and to put forward and promote ideas for a new structure consistent with the science, ethics and UNFCGG principles to replace the Kyoto Protocol. This would need rigorous homework as well as patient, proactive and visionary diplomacy. There is today a substantial body of work in India and sufficient expertise both inside and outside government to facilitate this ambitious task.

To illustrate, a series of studies and modelling exercises in India (Jayaraman et al. 2012;

Kanitkar et al. 2010) have thrown up interesting results and ideas for apportioning mitigation targets for all countries to keep global temperature rises to within desired limits. Later 
versions of this work are based on accumulated stocks of atmospheric carbon, which are of course the real trigger for climate change rather than annual flows. With a limit to the total carbon the atmosphere can hold for the given temperature range, the model allocates the remaining carbon budget to each country proportional to its population as its 'fair share' after accounting for historical emissions. Each country is then required to cut emissions, or be permitted to increase them, till its 'fair share' is reached. More than the detailed results or the model itself, which can be found in the referenced material, what is of interest here is that powerful ideas for national mitigation targets can be evolved based on uniformly applicable criteria (interestingly in a single framework so dear to the USA), science and ethics rather than ad hoc numbers. Similar carbon budget models are being developed elsewhere too. Such ideas need not be rigid formulaic solutions, but can form a reasoned basis for further negotiation with all the flexibility and pragmatism required.

\section{Domestic drivers and equity}

India's dilemma, to work out a climate position compatible with having a large section of its population in poverty with low human development while at the same time having significant industrial-economic strengths and technological capability, cannot be resolved in the international theatre alone. As noted earlier, India's climate policy has derived rather heavily from the standpoint of international relations. Most domestic measures were initiated by the Indian government as part of an externally driven agenda: India's National Action Plan on Climate Change, its decision to reduce emissions intensity, setting up an Expert Group for LowCarbon Development, all arose from a need to satisfy external interlocutors.

A climate policy without a sturdy domestic foundation will also be shaky. India has unfortunately not done nearly enough to build a strong domestic constituency favouring climate action.

No doubt there is today far greater awareness among policymakers, officials and academics, and sections of industry are motivated by cost savings through energy efficiency or new business opportunities such as in carbon credits or renewables. However, those most vulnerable to climate impacts such as farmers, fishermen or other coastal communities, those suffering from energy poverty and the poor in general are arguably the least involved in climate policy at any level. Indeed, how much the needs and interests of these sections are taken into account in formulating policy or in shaping and guiding programme implementation is a moot point.

While the interests of the most vulnerable groups are important in themselves, there is a double-edged problem with respect to climate policy. First, India's position at international climate meetings will increasingly suffer in credibility if its rhetoric on equity between nations is not matched by comparable concerns and actions to address equity within India. The charge that India is 'hiding behind the poor', ${ }^{9}$ even if not fully justified, has gained considerable currency. But equally, if not more important, potential climate victims in India have little or no stake in climate policy, even while developing countries as a whole, and Island States and LDCs in particular, have acquired a substantial voice at the international level. This situation in India needs to change, and urgently.

Some initial steps are being taken in India to formulate a co-benefits approach to domestic climate policy - that is, policies that yield developmental benefits while addressing climate change issues (Dubash 2012b). But these are yet to be adequately conceptualised and equity is far from being centre stage in such efforts. Developmental benefits from climate policy are unlikely to trickle down to vulnerable sections and require to be specifically planned for.

Energy access by the poor, increased availability of public transport especially by rail in preference to road, rural employment and energy-saving enterprises particularly in the non-farm sector, retarding urbanisation rates, and other such measures will require substantial redirection of mainly public but also private investment. Along with climate-proofing and adaptation programmes, these would build a powerful support base for climate action by India and boost India's negotiating strength in international fora. The circle of India's climate policy dilemma cannot be squared unless domestic equity is addressed specifically and directly. 


\section{Notes}

1 See Dubash (2012b); Bidwai (2011); Raghunandan (2011); Rajamani (2011), for discussion of India's position and role in the Durban summit.

2 For an exhaustive description and analysis of India's position from different perspectives, readers may see the collection of articles in Dubash (2012a, chapters 7-12); especially Dubash (2012c) in the same volume for an analytical account of the various contending positions within India on India's negotiating stance. Also Sengupta (2012) in the same volume.

3 These terms are together referred to in the parlance as CBDR\&RC but just CBDR is more commonly used, to the considerable detriment of understanding of and contributions to the debate, arising from neglect of the important role played by capacities of countries to respond to climate challenges with respect to both mitigation and adaptation.

4 See D. Raghunandan, Hokkaido G8 Summit and Climate Change, 2008, www.delhiscienceforum.net/ environment/275-hokkaido-g8-summit-aclimate-change-8-05-mem 16-o-html (accessed 17 April 2012) and other companion articles on the same website for a more detailed discussion of these developments in the G8/MEF

5 The perception that rising emissions of some large developing countries such as India are the dominant or even major factor causing climate change is erroneous in that temperature rises and other climate effects are caused by the accumulated concentrations of GHGs in the atmosphere rather than by current flows. India's cumulative emissions or contribution to stocks is substantially lower than that of most developed countries and even its current per capita flows are roughly a

\section{References}

Bidwai, Praful (2011) 'Durban: Road to Nowhere', Economic and Political Weekly, 31 December

Black, Richard (2011) 'Climate Change Talks End with Late Deal', $B B C$ News Online, 11 December 2011, www.bbc.co.uk/news/ science-environment-16124670 (accessed 25 March 2012)

Campaign for Progressive Climate Action and Policy (2009) India's Position on Climate Change: Statement Submitted to PM, quarter of the average for developed countries. The notion that somehow it is developing countries that are now mainly responsible for climate change has been assiduously, and apparently successfully, disseminated by many developed countries especially the USA.

However, the idea that rising emissions from large developing countries will increasingly represent a major problem for climate management is correct and has been discussed extensively in this article.

6 Quantum of emission reductions by large developing countries, when such emissions should peak and so on are not discussed here for want of space. Suffice it to note that absolute cuts by developing countries are not envisaged in the short term, and that developed and developing countries need to have different peaking years. For further discussion on this, see Kanitkar et al. (2010), Jayaraman et al. (2012).

7 Due to space constraints, I have not discussed here the important issues of when developing country emissions should peak and then start to decline, or the crucial role that accumulated stocks of carbon in the atmosphere rather than its annual emission flows (the former including historical emissions), play in determining climate change and the global average temperature.

8 These estimates are made in a confidential UN report leaked during the Copenhagen Summit and reproduced in The Guardian on 17 December 2009, www.guardian.co.uk/ environment/2009/dec/17/copenhagenemissions-cuts-future-temperatures (accessed 1 March 2012).

9 This was the evocative title of a report published by Greenpeace India in November 2007: the reference here is not intended to cite this report or to draw any inferences from it.

http://progressiveclimatepolicycampaignind.blogspot.in (accessed 2 March 2012)

Desai, N. (2011) 'Momentum from Durban', Business Standard, New Delhi, 15 December

Dubash, Navroz K. (ed.) (2012a) Handbook of Climate Change and India: Development, Politics and Governance, New Delhi: Oxford University Press

Dubash, Navroz K. (2012b) 'Looking beyond Durban: Where to from Here?', Economic and Political Weekly, 21 January 
Dubash, Navroz K. (2012c) 'Climate Politics in India: Three Narratives', in Navroz K. Dubash, (ed.), Handbook of Climate Change and India: Development, Politics and Governance, New Delhi: Oxford University Press

Intergovernmental Panel on Climate Change (2007a) Climate Change 2007: Contribution of Working Group III, Summary for Policymakers, www.ipcc.ch/pdf/assessment-report/ar4/wg3/ ar4-wg3-spm.pdf (accessed 17 April 2012)

Intergovernmental Panel on Climate Change (2007b) Climate Change 2007: Contribution of Working Group II: Impacts, Adaptation and Vulnerability, Summary for Policymakers, www.ipcc.ch/publications_and_data/ar4/wg2/ en/spm.html (accessed 17 April 2012)

Jayaraman, T.; Kanitkar, T. and D’Souza, M. (2012) 'Equity and Burden Sharing in Emission Scenarios: A Carbon Budget Approach', in Navroz K. Dubash (ed.), Handbook of Climate Change and India: Development, Politics and Governance, New Delhi: Oxford University Press

Kanitkar, T.; Jayaraman, T.; Sanwal, M.; Purkayastha P.; Talwar, R. and Raghunandan, D. (2010) 'Global Carbon Budgets and Burden Sharing in Mitigation Actions', paper presented to the Conference on Global Carbon Budgets and Equity in Climate Change, Tata Institute of Social Sciences, Mumbai

Kartha, S. and Erickson, P. (2011) Comparison of Annex 1 and non-Annex 1 Pledges under the Cancun Agreements, Stockholm Environment Institute, www.sei-international.org/ mediamanager/documents/Publications/ Climate/sei-workingpaperus-1 107.pdf (accessed 17 April 2012)

Levi, Michael (2011) 'A Misplaced Climate Celebration in Durban', Energy, Security and
Climate, Council on Foreign Relations, http://blogs.cfr.org/levi/2011/12/11/a-misplacedclimate-celebration-in-durban/\# cid= soc-emailat-blogs-a_misplaced_climate_celebratio-121111 (accessed 17 March 2012)

Raghunandan, D. (2012) 'India's Official Position: A Critical View Based on Science', in Navroz K. Dubash (ed.), Handbook of Climate Change and India: Development, Politics and Governance, New Delhi: Oxford University Press

Raghunandan, D. (2011) 'Durban Platform: Kyoto Negotiations Redux', Economic and Political Weekly, 31 December

Raghunandan, D.; Jayaraman, T.; Purkayastha, P; Karunakaran, C.E. and Venkateswaran, T.V. (2007) Climate Crisis: Challenges and Options, New Delhi: All-India Peoples Science Network and Tata Institute of Social Sciences

Rajamani, L. (2011) 'The Durban Dictionary', Indian Express, 25 December

Sengupta, Sandeep (2012) 'International Climate Negotiations and India's Role', in Navroz K. Dubash (ed.), Handbook of Climate Change and India: Development, Politics and Governance, New Delhi: Oxford University Press UNEP (United Nations Environment Programme) (2011) Bridging the Emissions Gap, www.unep.org/pdf/UNEP_bridging_gap.pdf (accessed 17 April 2012)

UNFCGG (2011) Establishment of an Ad Hoc Working Group on the Durban Platform for Enhanced Action, UNFCGC, http://unfcc.int/files/meetings/ durban_nov_2011/decisions/application/pdf/ cop 17 durbanplatform.pdf (accessed 17 April 2012)

UNFCGC (1992) United Nations Framework Convention on Climate Change, http://unfccc.int/ resource/docs/convkp/conveng.pdf (accessed 17 April 2012) 